\title{
Fractional Distillation- Ponchon Savarit and Mccabe Thiele Methods
}

\author{
Sunil Jayant Kulkarni \\ Datta Meghe College of Engineering, Airoli, Navi Mumbai, Maharashtra, India
}

*Corresponding Author: Dr. Sunil Jayant Kulkarni, Datta Meghe College of Engineering, Airoli, Navi Mumbai, Maharashtra, India

\begin{abstract}
The paper demonstrates use of two commonly used methods for fractional distillation column computations, namely Ponchon Savarit and McCabe Thiele. For multistage tray towers Ponchon Savarit method was first developed for the case of negligible heat losses. The use of the method is illustrated in the case studies. The method is rigorous and time consuming. The McCabe Thiele method is less rigorous as it doesn't enthalpy data. By McCabe Thiele method, Total 8 numbers of stages are required for desired separation. By Ponchon Savari Method, Reflux ratio R $=1.4$. Minimum numbers of were estimated to be 7 .
\end{abstract}

Keywords: Distillation, stages, equilibrium, reflux ratio, minimum number of stages

\section{INTRODUCTION}

Distillation is the process of separation and purification of different components of mixture of two or more organic liquids with appreciable difference in their boiling point. Fractionation is a multistage countercurrent distillation operation. For multistage tray towers Ponchon Savarit method was first developed for the case of negligible heat losses. The use of the method is illustrated in the case studies. The method is rigorous and time consuming. The McCabe Thiele method is less rigorous as it doesn't enthalpy data. This methods hinges upon the fact that, as an approximation, the operating lines on $\mathrm{x}$-y diagram can be considered straight for each section of fractionators [1].

\section{Fractional Distillation}

A typical fractional distillation column is shown in below Fig.1. A typical fractional distillation equipment contains overhead condenser, overhead accumulator, pumps, reboiler, feed/bottom exchanger, charge heater/steam preheater. The feed generally enters the column somewhere neat the middle of the column. Two sections of the column are rectifying or enriching section, located above feed tray and stripping section below the feed tray[2].

\section{Case Study 1}

Consider a saturated liquid mixture with composition, 0.7 mole fraction benzene and 0.3 mole fraction toluene is to be distilled continuously into a distillate product containing 90 mole percent benzene and bottom with 4 mole percent benzene. We assume column operates at atmospheric pressure with reflux ratio 2. For estimating number of plates, we plot $x-y$ diagram with diagonal as shown in fig.2. Then for saturated feed, we plot vertical q line. Carry out geometrical construction as shown in figure. First plotted a line through $(0.9,0.9)$ and $(0, \mathrm{Xd} /(\mathrm{R}+1))$. Stripping operating line is plotted through point of intersection of enriching operating line and $\mathrm{q}$ line through $(0.05,0.05)$. The numbers of stages are shown in the figure. As shown in fig.2, total 8 numbers of stages are required for desired separation. 


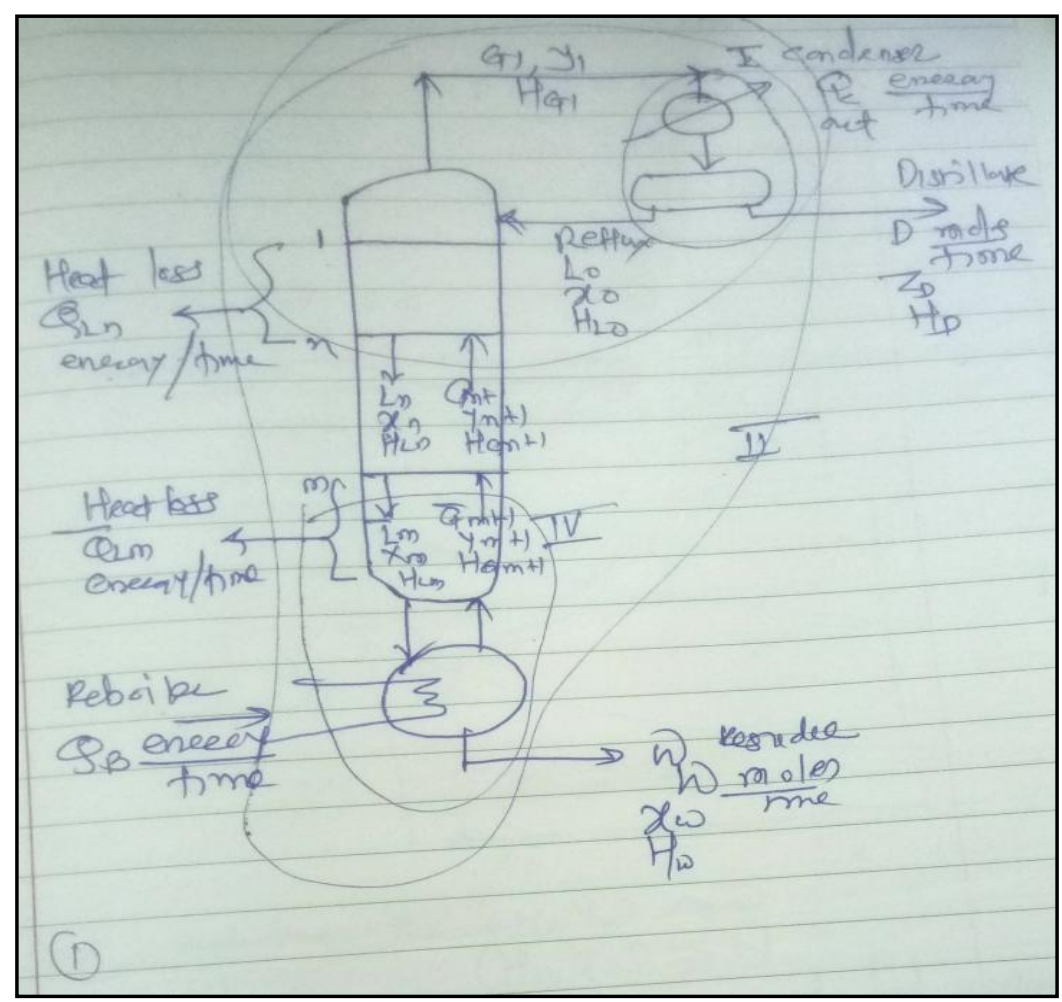

Fig1. Fractional distillation

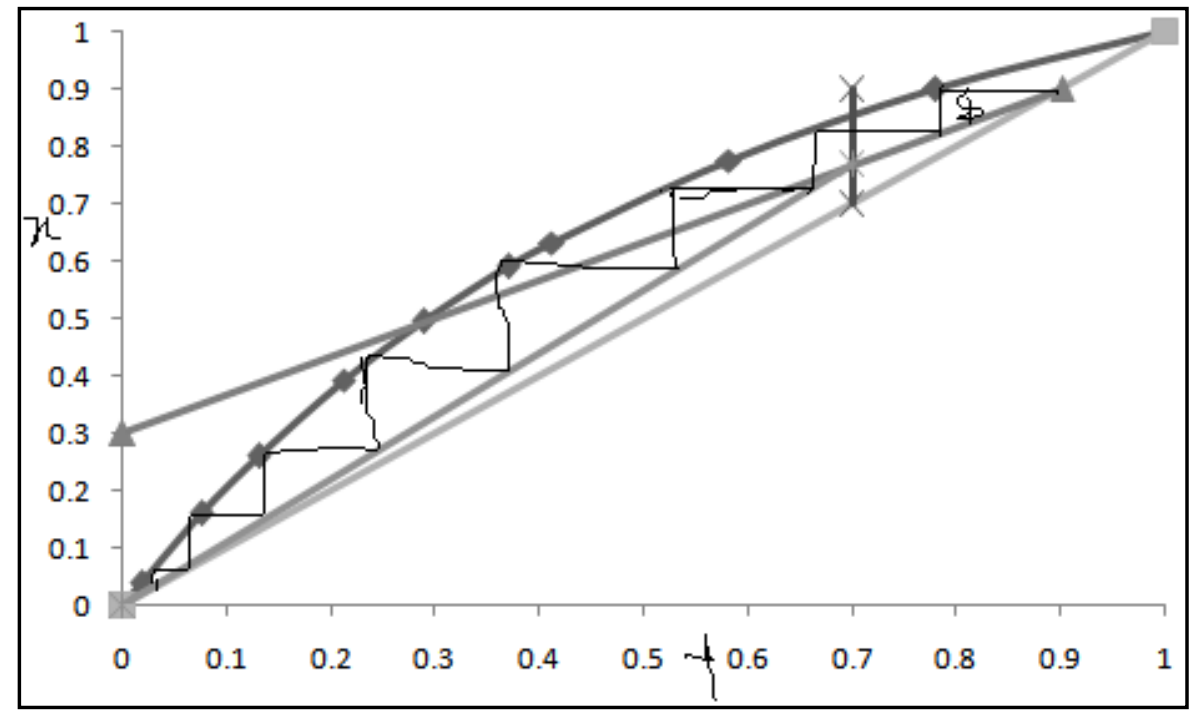

Fig2. McCabe-Thiele Method

\section{Case Study 2}

We consider $1000 \mathrm{~kg} /$ of ethyl benzene, heptanes mixture with 0.4 mole fraction of heptanes and 0.6 mole fraction of ethyl benzene. It needs to be fractionated to get 0.98 mole fraction heptanes and residue with 0.01 mole fraction of heptanes. Total condenser is used. The feed is saturated liquid. For this case to determine minimum reflux ratio by Ponchon Savarit method, we carry out geometrical construction as shown in fig. 3 . For $\mathrm{z}=0.4$, we get $\mathrm{H}_{\mathrm{F}}=22 \times 10^{3} \mathrm{Kj} / \mathrm{kmol}$ from the graph. For $\mathrm{X}_{\mathrm{D}}=0.98$, we get $\mathrm{H}_{\mathrm{D}}=21.5 \times 10^{3} \mathrm{Kj} / \mathrm{kmol}$ from graph. For $\mathrm{X}_{\mathrm{W}}=0.01$, we get $\mathrm{H}_{\mathrm{W}}=24.2 \times 10^{3} \mathrm{Kj} / \mathrm{kmol}$ from graph. T minimum reflux ratio a tie line through Feed Point $(F)$ when meets vertical line thtrough $X_{W}$ $=0.01$, determines $\mathrm{Q}^{\mathrm{II}}$ and when it meets vertical line through $\mathrm{X}_{\mathrm{d}}$, determines $\mathrm{Q}^{\mathrm{I}}$. These value were observed to be $-30 \times 10^{3}$ and $98 \times 10^{3} \mathrm{KJ} / \mathrm{kmol}$ respectively from graph. $\mathrm{H}_{\mathrm{G} 1}$, Enthalpy of vapours leaving top plate is $53 \times 10^{3} \mathrm{from}$ graph. Enthalpy of liquid entering first plate $=21 \times 10^{3} \mathrm{Kj} / \mathrm{kmol}$.

Reflux ratio $\mathrm{R}=(98-53) /(53-21)=1.4$

Minimum numbers of plates are determined as shown in fig.3. These were estimated to be 7 . 


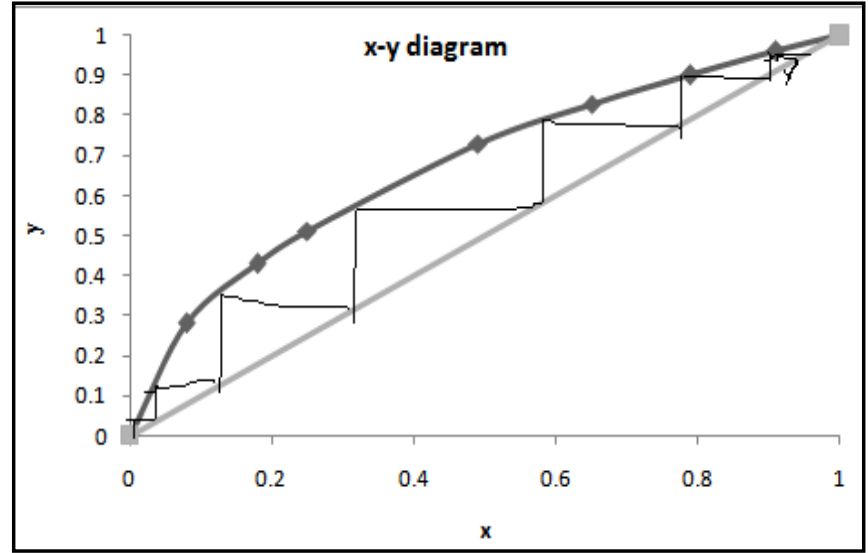

Fig3. $x$-y diagram

\section{CONCLUSION}

By McCabe Thiele method, Total 8 numbers of stages are required for desired separation. By Ponchon Savari Method, Reflux ratio $\mathrm{R}=(98-53) /(53-21)=1.4$. Minimum numbers of were estimated to be 7 .

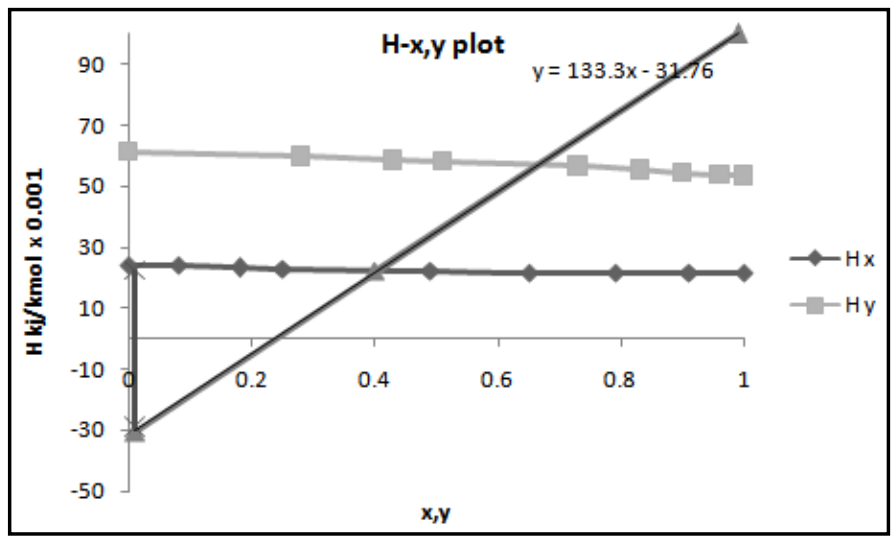

Fig4. H-x,y plot

\section{REFERENCES}

[1] Robert E. Treybal, Mass Transfer Operations, McGraw Hill International Editions, Chemical Engineering Series,Third Ed.,1980,367-402.

[2] K.D.Patil, Principles and Fundamentals of Mass Transfer Operation II, Nirali Publications, Vol.2, Fifth ed., 2002, 3.38-3.43.

\section{AUTHOR'S BIOGRAPHY}

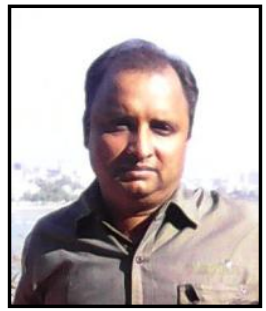

Mr. Sunil J. Kulkarni, has completed his Masters in Chemical Engineering from Tatyasaheb Kore Institute of Engineering and Technology, Warananagar in 2006. $\mathrm{He}$ is currently pursuing his $\mathrm{phD}$ in chemical engineering. He is working as Assistant Professor in Chemical Engineering Department of Datta Meghe College of Engineering, Airoli, Navi Mumbai, India. The author has 16 years of experience in teaching and research. He has published 200 international review and research papers and presented 15 research papers in international conferences. His area of research includes adsorption, environmental engineering and catalysis. He is editorial board member of more than 25 international journals and reviewed many international papers.

Citation: Dr. Sunil Jayant Kulkarni, (2018). Fractional Distillation- Ponchon Savarit and Mccabe Thiele Methods, International Journal of Petroleum and Petrochemical Engineering (IJPPE), 4(1), pp.15-17, DOI: http://dx.doi.org/10.20431/2454-7980.0401003

Copyright: (C) 2018 Dr. Sunil Jayant Kulkarni. This is an open-access article distributed under the terms of the Creative Commons Attribution License, which permits unrestricted use, distribution, and reproduction in any medium, provided the original author and source are credited 